\title{
Towards an Understanding of E-Government Induced Change - Drawing on Organization and Structuration Theories
}

\author{
Anne Fleur van Veenstra, Marijn Janssen, and Yao-Hua Tan \\ Faculty of Technology, Policy and Management, Delft University of Technology, \\ Jaffalaan 5, 2628 BX Delft, The Netherlands \\ \{a.f.e.vanveenstra,m.f.w.h.a.janssen,y.tan\}@tudelft.nl
}

\begin{abstract}
E-government research deals with 'wicked' problems that require multidisciplinary approaches to gain a full understanding. One of the main challenges of e-government is to induce change in the structure of public organizations to realize its full potential. This paper investigates e-government induced change using two complementary theoretical lenses applied to an egovernment case study. We use organization theories to explore aspects of organizational structure that may change when implementating e-government and structuration theory to investigate how these aspects are affected by human action within its social structure. This combination allows us to investigate the discrepancy between the ambitions of e-government induced change and the actual changes accomplished in practice. Our analysis shows that using these two frames gives us better insight into the thorny subject of e-government than using a single theory. Further research should look into how these theories can be used to deepen our knowledge of e-government.
\end{abstract}

Keywords: E-government, organizational change, organization theory, structuration theory, multidisciplinary approach.

\section{Introduction}

Over the past decades the research field of e-government "has advanced past the stage of infancy" [1, p. 2]. A recurring theme in studies of the e-government research field, however, is that most e-government research is empirically based, lacking theoretical foundations [2-4]. One reason for this lack of common foundations is that egovernment is essentially a multidisciplinary research field dealing with 'wicked', unstructured problems, and "[i]ntegration and interdisciplinarity has proved to be more and more difficult as more disciplines with different paradigms and standards begin to interact" [1, p. 23]. To advance interdisciplinary understanding of egovernment, this paper explores the use of different theoretical lenses for explaining challenges e-government implementation encounters in practice.

One of the main challenges for e-government is to realize organizational change to realize the full potential of information technology (IT), thereby improving operations [5-7]. For public agencies, this means that previously stove-piped organizations will 
need to break down the silos in which departments operate and change from hierarchical - vertically oriented - organizations into network-centric - horizontal organizations [6]. However, empirical studies suggest that, in reality, the introduction of IT not often changes institutions and, rather, often reinforces current work practices and organizational structures [8-10]. This has resulted in a gap between the promises and actual realization of e-government induced change. This paper aims to understand this gap and to deepen our knowledge on how these organizations may reap the full benefits of e-government. E-government induced change is among the complex and unstructured research problems that have been mentioned to benefit from using a multidisciplinary approach [11]. To understand the differences between the objectives and promises of e-government induced change and its achievements in practice, we use two different theoretical strands.

One theoretical strand encompasses theories on organizational structure. Aspects of organizational structure and IT-induced change will be identified. The other strand of literature that is used is structuration theory. Structuration theory can be used to study the complexity of a change process by looking at it as the result of the duality of agency behavior and social structure. We will apply these two theoretical lenses to a case study in the Netherlands to see how they enhance our understanding of egovernment. This paper continues with introducing aspects of organizational structure. Then, structuration theory will be discussed. Next, the research approach of applying this combination of theories to a case study of e-government in the Netherlands is presented, followed by the case study description and its findings. Finally, we present conclusions and recommendations for future research.

\section{Theories on Organizational Structure}

Since the emergence of the information society, networks and organizations adopting a network approach are on the rise [12]. Effective e-government also requires public organizations to adopt a network orientation [6], governed by interdependent relations that collaborate to achieve mutual benefits [13]. Traditionally, however, government organizations are organized as bureaucracies: functional hierarchies that are made up of stove-piped departments supported by fragmented information systems. Characteristics of bureaucracy include a specialization of labor, a hierarchy of authority, a system of rules limiting discretionary power of individuals and written records of activities. Although, according to Weber [14], bureaucracies represent the most efficient organizational form, nowadays, they are most often linked with concepts such as red tape and inefficient decision structures: "the very structures that ensure continuity and stability are major inhibitors of change" [6, p. 66]. To make a shift from a hierarchy to a network-oriented organization requires changes that will alter work practices and organizational structure. The increasing use of IT is generally considered as one of the main drivers of this shift in organizational structure. In this section we indentify from literature which organizational aspects likely change supporting e-government implementation.

Researching which organizational characteristics fit certain circumstances, Galbraith identified three characteristics of the structure of an organization under uncertainty: rules and procedures, decentralization of decision making, and 
professionalization of the work force [15]. Another aspect of organizational structure is the (set of) mechanism(s) coordinating activities. Mintzberg distinguishes five different mechanisms defining five structures [16]. While informal coordination mechanisms are used in very simple as well as in very complex organizations, direct management is used in smaller organizations. As soon as organizations grow further, standardization is used as the main coordinating mechanism. Mintzberg distinguishes standardization of tasks, outputs and abilities. In addition to specialization of labor, centralization of decision-making and formalization of tasks, organizational size and coordination mechanism can, thus, be considered as aspects subject to change.

Next, we look at which of these may be changed to support e-government implementation. However, there are few conclusive studies on changes in organizational structure as a result of IT-implementation. IT has been said to change managerial structure by cutting out the middle management [17], thereby increasing centralization of decision-making [18]. Pfeffer and Leblecici, on the other hand, found that IT-implementation correlates with decentralization of decision-making while it negatively coincides with the degree of formalization of decision rules [19]. There is one main aspect that has been identified as determining organizational structure and being influenced by IT and that is the height of transaction costs.

Transaction costs are those costs involved in coordinating economic transactions. Among the factors influencing the height of the transaction costs are informationuncertainty and complexity, frequency of the transaction and asset specificity. When transaction costs are high it may make more sense to incorporate certain activities into the hierarchy, whereas when they are low, they may be best left to the market [20]. For a shift towards a network structure, lower transaction costs are, thus, considered a prerequisite - otherwise, activities may best be incorporated [14]. Transaction costs are widely found to decrease dramatically as a result of diminished asset specificity and complexity of product information [21]. IT, thereby, allows for room for outsourcing activities and further specialization of organizations into defining their core activities [22]. This, in turn, will affect the formation of networks of specialized organizations.

Yet another aspect of organizational structure is considered influential in determining change. Some claim that the structure of organizations may not be so much influenced by rational decisions or economic measures as held by the theories described in the previous section. DiMaggio and Powell explain the abundance of bureaucratic forms in organizations not as a result of them being the most efficient organizational structure, but as a result of a consensus on bureaucracy being the most common form of organizations [23]. Instead of the rationale organizations functioning in the most optimal form, these authors consider institutions to play a large role in determining organizational structure. Institutions are the formal and informal rules that constrain human economic behavior, such as actor behavior and interactions, legal rules and culture, values and attitudes. So far, IT has been observed to change institutions only indirectly [24-26].

Although much research has been done on how IT affects organizational structure, findings regarding which organizational aspects change are still inconclusive and sometimes contradictory. A second line of research is, therefore, used to further investigate the impact of IT on organizational aspects in practice. 


\section{Structuration Theory}

The organization theories mentioned in the previous section incorporate an implicit teleological assumption that changes in structure occur as a result of purposeful actions, seeing change "as a repetitive sequence of goal formulation, implementation, evolution, and modification of goals based on what was learned" [27]. A different way of looking at organizational change is by taking a dialectic perspective [27, 28]. This perspective understands change, instead of as an objective, discernable sequence of action, as a mutually influential process of action and structure [27, 28]. Change occurs, in this view, as a result of human actions shaping social phenomena as well as them being shaped by social structure. Hence, this theory is referred to as structuration theory $[29,30]$. The best-known work on structuration theory is that of the sociologist Anthony Giddens. In his view, structure is reproduced by ongoing human action either reinforcing or changing structure. At the same time, structure enables and constrains human action. "Thus, social phenomena are not the product of either structure or agency, but of both" [31, p. 129]. In Giddens' view structure and agency are a mutually constitutive duality and the two cannot be examined separately.

Many authors writing on information systems have used structuration theories to explain changes in organizations that occur as a result of implementing IT [31, 32]. These authors have both sought to apply the theory as well as extend it to fit studies of technology, something Giddens did not write about extensively [31]. Orlikowski, for instance, was concerned with understanding the role of the social structure in the adoption and use of IT "as a process of enactment" and extended theory to the domain of information systems [31, p. 404]. She distinguishes different forms of interplay between technology and structure, which she called the duality of technology. This duality can be conceptualized as follows:

"[T] echnology is physically constructed by actors working in a given social context, and technology is socially constructed by actors through the different meanings they attach to it and the various features they emphasize and use. However, it is also the case that once developed and deployed, technology tends to become reified and institutionalized, losing its connection with the human agents that constructed it or gave it meaning, and it appears to be part of the objective, structural properties of the organizations." [32, p. 406]

Others have sought to apply structuration theory to understand and explain the adoption of new information systems in practice [33-38], e.g. to study the influence of e-government policies on IT-systems or the use of prototyping in implementing a standard for data exchange. This type of changes affecting organizations share similarities to the type of phenomena Giddens aimed to understand, as "he was particularly interested in large-scale change episodes" [35, p. 3].

A concept worth mentionng for understanding how the processes of structuration and enactment takes place is appropriation, which refers to technology not being implemented in an organization in a predestined manner, but rather through ongoing human action [32, 37], appropriating technology "faithfully or unfaithfully" [31, p. 141]. Whether structure can be embodied in technology is, however, still contested; according to Giddens, structure cannot be embedded in technology, as, by his definition, it cannot be separated from human action [31], but others hold that that 
"many institutions preserve structural "traces" in physical artifacts" [38, p. 585]. While this represents one part of the duality, the other part is represented by the use of technology as an enabling and constraining influence on the structuring of human action.

For explaining organizational change as a result of IT implementation, structuration theory holds that the social structure influences - through human action - IT development and implementation, as well as it, in turn, reinforces or transforms structure, again through human action. For e-government, this means that organizational change occurs as a result of IT changing work practices, and at the same time, IT-implementation is influenced by the social structure through the process of human action appropriating technology. Change is no longer an objective process that can be discerned and predicted by identifying forces that influence change, but it also needs to be looked at from a perspective of human action giving meaning to technology. Technology is, thereby, no longer independently influencing organizations and institutions, but it is, rather, produced by organizations and institutions through human action. In the same line, it is argued that e-government policies enact with public sector IT [39] by influencing information systems' functionalities. In practice, a result of the process of structuration is that changes of organizational structure often have unintended outcomes.

\section{Research Method}

The basic premise of this paper is that the combination of both theoretical lenses presented in the previous sections will allow us to investigate e-government induced change by investigating changes in (aspects of) organizational structure. We use organizational theory to project expected changes and structuration theory to investigate how these changes take place in practice. To find out how these two theoretical lenses can be used to deepen our understanding to e-government, we examine a case study from the Netherlands. This case study concerns the adoption of the international financial reporting standard XBRL (acronym of eXtensible Business Reporting Language) for legally required financial reports of businesses. It is considered an appropriate case for investigating e-government induced change, as it captures the involvement of many stakeholders, new technologies and the need to change structures and adapt to new roles. Furthermore, a change in organizational structure was a specific goal of implementing the standard. Although one case study is generally considered to be insufficient for making generalizations [40], our objective is to explore the explanative power of these two theoretical strands in the field of e-government.

A retrospective view on the case was created by carrying out fifteen semistructured interviews over the course of January and February 2010. Such a perspective allows us to understand the forces and factors that were in place for realizing organizational change as well as how the process of change took place. The fifteen interviewees included three project managers of government organizations involved in implementing and maintaining the government infrastructure and systems for XBRL, five representatives of businesses from different sectors and varying size for understanding the user perspective, three accountants, two software companies 
developing software packages for financial reporting, and two banks that are currently implementing XBRL in their organizations. All interviews lasted between one hour and an hour and half. Most interviews were conducted by two researchers comparing results afterwards; some were conducted by one interviewer only.

To get new insight into the very process of e-government implementation, we investigate how aspects of organizational structure are influenced by IT-adoption and the process of structuration. Rather than trying to test hypotheses, the interviews were aimed at gathering qualitative data. We started out by asking about the objectives and intentions for implementing the standard and (if mentioned) for changing the organization. Using organization theory, we enquired after specific aspects of organizational structure, such as decision-making authority and the degree of standardization and how they are to be changed. Then, based on structuration theory, we formulated questions on how different actor groups appropriated and shaped IT and its implementation. We enquired after the values attached to the information system and the changes in work practices, and we set up a timeline of actions undertaken by different action groups influencing implementation of the standard that was adjusted after each interview. The purpose of these questions was to compare the intensions of implementation with the outcomes in practices. By using these two theoretical lenses at the same time, we sought to get greater insight into how egovernment implementation determines the structure of public organizations.

\section{Case Study}

The introduction of the international XBRL standard in the Netherlands was set out to change the process of legally required financial reporting by businesses. Instead of all government agencies defining their own requirements for financial reports, a taxonomy was created to harmonize definitions used by the Dutch government in the financial domain. Furthermore, a common process infrastructure under development were to be used for submitting all financial reports. Although the XBRL standard can be used for financial reporting across many sectors, the current project set-up includes a few specific legally required reports: (profit) tax filing at the Inland Revenue Service (IRS), the submission of financial year reports at the Chamber of Commerce and the submission of data to the national bureau for statistics (CBS). The process infrastructure developed to facilitate data exchange consists of a unified gateway for bulk data to government information systems. While the current structure of organizations concerned with financial reporting can be defined as a hierarchical command-and-control situation in which the government agencies enforce their standards onto the market, XBRL implementation is expected to allow for the creation of value chains. As generating financial reports will be done using an open standard, organizations are able to innovate and new applications may emerge as well as new organizations developing new services. This likely results in a new situation in which government agencies remain in control of the interpretation of financial data and the decision-making process, but the process of creating reports will take place within a value chain that enables innovation.

Implementation of XBRL started in 2004 with the set-up of the Dutch Taxonomy project (NTP). This project set out to harmonize all definitions and items used by the 
government in the financial domain in their contact with businesses. Two years later, also a generic infrastructure project was carried out drawing up requirements for the functionalities necessary for a new process infrastructure for financial reporting based on XBRL. When both the development of the taxonomy and the process infrastructure requirements were published (first version) in 2006, three (semi-)public agencies (IRS, Chambers of Commerce and CBS) signed an agreement that they will implement XBRL. This agreement was also signed by representatives of businesses, accountants and software vendors to stimulate the use of XBRL for financial reporting. Then, as a result of political priorities, the project was appointed to contribute to the central government agenda to achieve a decrease of the administrative burden of businesses. In 2007, the central government estimates that around 350 million euro's worth of administrative tasks of businesses can be cut and around a million tax filings using XBRL will be achieved yearly by 2008. Also in 2007, the first versions of the process infrastructure developed for exchanging data based on XBRL are ready. It had been decided that it should be maintained by the central government IT maintenance agency (Logius) and from 2008 onward the old process infrastructure for financial data exchange based on XML is phased out slowly. Furthermore, a novel authentication mechanism is included in the process infrastructure (AuSP), a step that was not part of the process before.

In 2009, however, it appeared that none of the above mentioned goals were met or will be met any time soon. The administrative burden will not be diminished and few yearly reports or tax filings were submitted using XBRL. Furthermore, while the unified gateway is still under development, no new applications or service developments are emerging yet. Besides the objectives not being met, another problem encountered is that for filing profit taxes a local version of the taxonomy is implemented, thereby not complying with the international XBRL standard. The reason for this diverging standard is that it would be easier to implement, spurring adoption of XBRL in the future. Generally, businesses and government agencies claim that they are not yet ready for implementing the XBRL standard or for building an extension to the process infrastructure. They say that they are waiting for the central government to make decisions before they will invest. Therefore, in 2009 the project was handed over to Logius altogether and a steering group consisting of senior representatives of all Ministries involved was appointed. This means that instead of the expected value chains emerging, change and implementation is still policy-driven, carried out by the public sector. Although the emergence of value chains is still likely to happen eventually and organizations in the new situation work within a network, only limited changes to adjust to their new role in the network can be seen.

\section{Findings and Discussion}

Based on the case study in the previous section, we now take a look at aspects of organizational structure and the process of change. Findings from the case study are summarized in Table 1. The factors from organizational theory are used to predict the type of organization structure that is expected to emerge. These are shown in the lefthand column. Some of these predictions proved to be correct, but most of them were not realized. Explanations based on structuration theory are shown in the right-hand column to explain why predictions from organization theory were (not) realized. 
Table 1. Aspects of organizational structure predicted to change and their behavior as a result of the process of structuration

\begin{tabular}{l} 
Aspects of organizational structure \\
influenced by IT-implementation \\
\hline Standardization is likely to spur the \\
emergence of a network structure as a result \\
of diminishing transaction costs through the \\
use of a single standard for financial \\
reporting (XBRL) as well as specialization \\
into core activities of organizations. \\
The more transparent nature of standardized \\
reporting is likely to change the authority \\
structure. Hierarchical levels will likely be \\
cut down and a greater degree of \\
horizontalization is likely to emerge in the \\
form of value chains of specialized \\
organizations.
\end{tabular}

Institutions (either a law or a common practice) should spur and accelerate uptake of the XBRL-standard and allowing for it to spread throughout different sectors.

The main coordination mechanisms changes from informal mechanisms (before introduction of IT) to standardization of data (previous data standards for each government organization) to standardization of procedures (by standardizing all financial reporting and they way it is exchanged).

Centrality of decision making is likely to increase as a result of standardization. A central organization is in charge of maintenance as well as implementation.
Degree of change as a result of process of structuration

Network structure did not emerge, nor was more specialization observed; the appropriation of technology results in the creation of a diverging standard (for the purpose of simplifying a single process), thereby reducing the degree of standardization across sectors and inhibiting reduction of transaction costs.

The authority structure was hardly changed, only an additional control step was added, by adding an extra step to the process: an authorization functionality that requires businesses to identify themselves in a way that was not necessary before. Furthermore, the steering committee did not have the power to steer across organizations, as a result of the current siloed structure.

Appropriation of the new standard is unlikely to take off as long as the government does not set the right example and facilitate uptake by firmly institutionalizing the standard in its own work practices.

A common data standard has emerged; XBRL will become the one standard for financial reporting. Before standardization emerged, however, a long period of negotiation took place on the scope of the implementation, the maintenance structure and the process architecture. For strategic reasons, organizations still try to influence these 'secondary' processes that are the conditions for standardized reporting.

As long as the process infrastructure is not fully implemented, this leaves room for decentralist forces and decision-making and individual agencies decide to use the standard or not based on their own criteria, as happened in the case of the diverging standard for profit taxes. At the same time, the process of structuration has also led to a central role of the government in implementing XBRL. 
The main driving force of implementation of the XBRL standard was its ability to enable the formation of value chains or value networks as a result of diminished transaction costs and a standardization of data exchange and procedures. New services, such as benchmarking, were expected to emerge on the basis of XBRL and the administrative burden of businesses was supposed to be decreased. In reality, however, most of the organizational structure remains as it is and very little of an emerging network structure can be observed yet; the central government still remains in control of the process and has even gained tighter control than before. As a result of tensions in the implementation process, this is currently endorsed by many of the parties involved. Even though all parties claim they are committed to the standard, in reality they do not change as a result of the promise of decreased transaction costs alone. Instead, they adhere to the current structure in which they operate and to which they are used. Businesses we interviewed said they would wait with adopting XBRL until it would become legally required (and thereby firmly institutionalized).

Coordination mechanisms in the past were mainly informal, involving all major stakeholders. Therefore, for the implementation process to be successful, appropriation will have to take place in a manner in which all parties are involved in the decision-making process and a solution will need to be acceptable to all actors having the power to block the implementation process. In the future, the far-reaching implementation of the XBRL standard will give rise to new types of coordination mechanisms as tasks will be shifted towards the maintenance of the taxonomy and a standardization of procedures is likely to emerge. This can be seen as the second part of Orlikowski's duality, where the use of technology in human action shapes renewed social structure. The case study shows that the lack of collaboration among stakeholders is part of the siloed social structure at the start of the implementation which reinforces the existing social structure instead of resulting in change, as decision makers are not allowed to take decisions concerning multiple organizations. This can also explain why the elements developed are optimized within their own organizational context, but could not be integrated as dependencies between these elements were not addressed.

Factors determining organizational structure that were relevant in this case study most often led to different outcomes than predicted by organizational theory. Using structuration theory, we gained insight in the change process where enactment and appropriation of technology leads to different outcomes as a result of the mutual influence of human action and social structure. At the same time, we did not find evidence that the changes in the aspects of organizational structure that were identified may never become reality. By the time e-government implementation becomes part of the social structure, it may well be possible that a greater degree of horizontalization emerges. Thus, we found structuration theory to be powerful in explaining outcomes of government induced change that is enabled and constrained by human action within its social structure and, thereby, powerful for explaining individual cases. At the same time we found that it cannot be used to make any general predictions concerning changes in organizational structure like organizational theory may well be able to.

Therefore, we suggest that further research focuses on combining both theoretical strands to deepen our understanding of how e-government induced change takes place in practice, as well as to be able to make better predictions on how this change will 
occur. Our case study research shows that using the combination of these two complementary theoretical lenses explains better the practice of e-government implementation than using one theoretical strand. By investigating how the forces influencing e-government induced change identified from organization theory interfere with the process of structuration, we are able to give some explanation on why the achievements of e-government lag behind the objectives and promises. Further research should find out whether these theoretical lenses can also be applied to other e-government implementation processes. A limitation of this research is that a retrospective view was created instead of carrying out a longitudinal study. While this did not hinder our purpose of determining the power of these two theories, we suggest to use a longitudinal approach in further research on e-government implementation.

\section{Conclusion}

E-government implementation requires organizational change to realize its full potential by changing public organizations from hierarchies into having a networorientation. Change in public organizations, however, is a complex and unpredictable process. Current literature on e-government is trying to grasp the complexity of the matter and is in search for multidisciplinary approaches for further investigations. This paper explores the gap between the promises and achievements of e-government induced change. Using two complementary theoretical lenses, we investigate how they can be used to gain greater insight in this gap. We combine organization and structuration theory by using the former category to identify how aspects of organizational structure change under influence of IT and the latter to be able to explain the working of these factors under the process of structuration. This allowed us to investigate the differences between the outcomes of change and the objectives of the change process.

By investigating a case study of e-government implementation in the Netherlands we found that while organization theories are useful for predicting change, they often fail to give insight into why certain predictions do not materialize. And while structuration theory can explain how IT shapes and is shaped by human action within its social structure, it does not allow generalizations to be made on the use of IT in the public sector. In our case study we saw the promised decrease of transaction costs severely curbed by a social structure unable to understand or materialize this decrease and, instead, decided to diverge from the design to meet the project deadline. The process of appropriation, in this case, led to the adoption of different technologies, instead of to a greater degree of standardization as expected by organization theory. We, therefore, conclude that combining these theories can be used to deepen our understanding of the challenges e-government implementation encounters in practice.

\section{References}

1. Scholl, H.J.: Electronic Government: A study Domain Past its Infancy. In: Scholl, H.J. (ed.) Electronic Government: Information, Technology and Transformation. M.E. Sharpe, Armonk (2009)

2. Heeks, R., Bailur, S.: Analyzing e-government research: Perspectives, philosophies, theories, methods, and practice. Government Information Quarterly 24, 243-265 (2007) 
3. Gronlund, A., Horan, T.A.: Introducing e-Gov: History, Definition, and Issues. Communications of the Association for Information Systems 15, 713-729 (2005)

4. Yildiz, M.: E-government research: Reviewing the literature. limitations, and ways forward. Government Information Quarterly 24, 646-665 (2007)

5. Gregor, S., Martin, M., Fernandez, W., Stern, S., Vitale, M.: The transformational dimension in the realization of business value from information technology. Journal of Strategic Information Systems 15, 249-270 (2006)

6. Bannister, F.: Dismantling the silos: extracting new value from IT investments in public administration. Information Systems Journal 11, 65-84 (2001)

7. Hazlett, S.-A., Hill, F.: E-government: the realities of using IT to transform the public sector. Managing Service Quality 13, 445-452 (2003)

8. West, D.M.: E-Government and the Transformation of Service Delivery and Citizen Attitudes. Public Administration Review 64, 15-27 (2004)

9. Fountain, J.E.: Building the virtual state: information technology and institutional change. Brookings Institution Press, Washington (2001)

10. Kraemer, K., King, J.L.: Information Technology and Administrative Reform: Will E-Government Be Different? International Journal of Electronic Government Research 2, 1-20 (2006)

11. Scholl, H.J.: Central research questions in e-government, or which trajectory should the study domain take? Transforming Government: People, Process and Policy 1, 67-88 (2007)

12. Castells, M.: The Rise of The Network Society. Blackwell Publishing, Malden (2000)

13. Powell, W.W. (ed.): Neither Market nor Hierarchy: Network Forms of Organization. Sage Publications, London (1991)

14. Weber, M.: Wirtschaft und Gesellschaft, Tubingen (1972)

15. Galbraith, J.: Designing Complex Organizations. Addison-Wesley, Reading (1973)

16. Mintzberg, H.: Structure in Fives: Designing effective organizations. Prentice Hall Business Publishing, New Jersey (1983)

17. Leavitt, H., Whisler, T.L.: Management in the 1980s. Harvard Business Review 36, 41-48 (1958)

18. Schwarz, G.M., Brock, D.M.: Waving hello or waving good-bye? Organizational change in the information age. The International Journal of Organizational Analysis 6, 65-90 (1998)

19. Pfeffer, J., Leblebici, H.: Information Technology and Organizational Structure. The Pacific Sociological Review 20, 241-261 (1977)

20. Williamson, O.E.: Markets and Hierarchies: Analysis and Antitrust Implications. Free Press, New York (1975)

21. Malone, T.W., Yates, J., Benjamin, R.I.: Electronic Markets and Electronic Hierarchies. Communications of the ACM 30, 484-497 (1987)

22. Pralahad, C.K., Hamel, G.: The core competence of the corporation. Harvard Business Review 69, 81-93 (1990)

23. DiMaggio, P.J., Powell, W.W.: The Iron Cage Revisited: Institutional Isomorphism and Collective Rationality in Organizational Fields. American Sociological Review 48, 147-160 (1983)

24. Gascó, M.: New Technologies and Institutional Change in Public Administration. Social Science Computer Review 24, 6-14 (2003)

25. Fountain, J.E.: Building the Virtual State: Information Technology and Institutional Change. Brookings Institution Press (2001) 
26. Kraemer, K.L., King, J.L.: Information Technology and Administrative Reform: Will e-Government be Different? International Journal of Electronic Government Research 2, 1-20 (2006)

27. van de Ven, A.H., Poole, M.S.: Explaining Development and Change in Organizational The Academy of Management Review 20, 510-540 (1995)

28. Robey, D., Boudreau, M.-C.: Accounting for the Contradictory Organizational Consequences of Information Technology: Theoretical Directions and Methodological Implications. Information Systems Research 10, 167-185 (1999)

29. Giddens, A.: Central Problems in Social Theory. Social Analysis. University of California Press, Berkeley (1979)

30. Giddens, A.: The constitution of society: Outline of the theory of structuration. Polity, Cambridge (1984)

31. Jones, M.R., Karsten, H.: Giddens's Structuration Theory and Information Systems Research. MIS Quarterly 32(1), 127-157 (2009)

32. Orlikowski, W.J.: The Duality of Technology: Rethinking the Conept of Technology in Organizations. Organization Science 3(3), 398-427 (1992)

33. Pozzebon, M., Pinsonneault, A.: Challenges in Conducting Empirical Work Using Structuration Theory: Learning from IT Research. Organization Studies 26(9), 1353-1376 (2005)

34. Orlikowski, W.J.: Using Technology and Constituting Structures: A Practice Lens for Studying Technology in Organizations. Organization Science 11(4), 404-428 (2000)

35. Gil-Garcia, J.R., Canestraro, D., Costello, J., Baker, A., Werthmuller, D.: Structuration Theory and the Use of XML for Web Site Content Management in Government: Comprehensive Prototyping as an Induced Change Episode. In: Proceedings of the American Society for Information Science and Technology (2008)

36. Chu, C., Smithson, S.: E-business and organizational change: a structurational approach. Information Systems Journal 17, 369-389 (2007)

37. Poole, M.S., DeSanctis, G.: Structuration Theory in Information systems Research: Methods and Controversies. In: Whitman, M.E., Woszcynski, A.B. (eds.) The Handbook for Information Systems Research (2002)

38. Cordella, A., Iannacci, F.: Information systems in the public sector: The e-Government enactment framework. Journal of Strategic Information Systems 19, 52-66 (2010)

39. Poole, M.S.: Response to Jones and Karsten, Giddens's Structuration Theory and Information Systems Research. MIS Quarterly 33(3), 583-587 (2009)

40. Yin, R.K.: Case Study Research: Design and methods. Sage, Thousand Oaks (1989) 